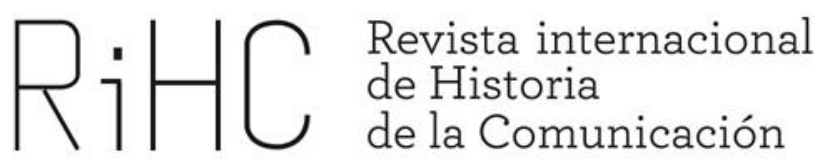

\title{
ICONOGRAFÍA PUBLICITARIA DE RAFAEL PENAGOS EN LA ESFERA
}

DOI: http://dx.doi.org/10.12795/RiHC.2015.i05.07

María Arroyo Cabello

Universidad Católica San Antonio de Murcia

msarroyo@ucam.edu

Recibido: 10-11-2015

Aceptado: 16-12-2015

Resumen: El objeto de este artículo es recopilar la producción publicitaria de Rafael Penagos en la revista gráfica La Esfera y analizar las ilustraciones comerciales para la perfumería Floralia. Para ello se ha realizado una revisión bibliográfica y hemerográfica, y un análisis de contenido.

El estudio revela en primer lugar, que Penagos colaboró asiduamente -entre 1915 y 1920- en las páginas publicitarias de La Esfera con dibujos la mayoría para Floralia.

En segundo lugar, en los anuncios ilustrados para esta marca se encuentra ya el prototipo femenino que tanta repercusión alcanzaría en la burguesía madrileña de los años veinte.

Palabras clave: La Esfera, perfumería Floralia, imagen femenina, Rafael Penagos.

Abstract: The article aims to collect the advertising work of Rafael Penagos in the graphic magazine La Esfera and to analyse the commercial illustrations for the perfume 
shop Floralia. A bibliographical and press review has, therefore, been carried out together with an analysis of contents.

The study finds first that Penagos was an assiduous collaborator-between 1915 and 1920- in the pages of the La Esfera with illustrations, most of which were for Floralia.

Secondly, we can also already find in the illustrated advertisements for Floralia the women's prototype that would become so influential in the bourgeoisie of Madrid of the 1920s.

Keywords: La Esfera, Floralia perfumary, feminine image, Rafael Penagos.

\section{Introducción}

Rafael Penagos goza de un prestigio ganado a pulso con su ingente producción artística en todo tipo de soportes, que su hijo calcula en "unas quince mil obras, entre dibujos, ilustraciones, portadas, carteles y retratos" (Campoy, 1983:9). Un gran dibujante del siglo XX reconocido tanto dentro como fuera de España, con numerosos premios en concursos de carteles convocados por reputadas marcas e instituciones como la casa Gal o el Círculo de Bellas Artes de Madrid, y que en 1925 recibía la medalla de Oro en la Exposición Internacional de Arte Decorativo de París subrayando así la importancia internacional de su figura.

A pesar de ello es un artista que, durante mucho tiempo, ha pasado desapercibido en su patria hasta que en 1989 -al cumplirse cien años de su nacimiento- la Fundación MAPFRE lo rescató del olvido organizando una exposición antológica del artista y editando un libro-catálogo que recoge lo más significativo del arte de Penagos. Poco antes, en 1982 la entidad creó, con carácter anual, el Premio Penagos de Dibujo para artistas españoles e hispanoamericanos; a partir de 2008 el premio se otorga como reconocimiento a la trayectoria profesional de un dibujante vivo de relevancia nacional o internacional.

Aparte del estudio introductorio de Antonio Manuel Campoy en el libro-catálogo ya citado y del texto que Francisco Javier Pérez Rojas escribió para las colecciones de MAPFRE en 2006, no se conoce ninguna otra monografía sobre Penagos.

Es verdad que muchos autores contemporáneos suyos escribieron artículos en la prensa desde Julio Camba, Cesar González-Ruano, Tomás Borrás, Edgar Neville, Miguel Mihura, Julio Caro Baroja, Josefina Carabias, Federico García Sanchiz, Serrano Anguita, José Francés y un largo etc., pero se trata de vivencias y recuerdos de personas que compartieron con él sus triunfos.

Sin embargo, apenas se ha estudiado su figura desde el ámbito académico: que nos conste, sólo Estrella de Diego publicó en 1983 un artículo, extracto de su Memoria de licenciatura. Por supuesto que se encuentran abundantes referencias a Penagos en 
libros y artículos acerca de la ilustración publicitaria en las primeras décadas del siglo XX: De Andrés (1985), (Pérez Rojas,1990), Lozano Bartolozzi (1992), Satué (1997), Alvarado y De Andrés (1998), Carulla\&Carulla (1999), Eguizábal (1998, 2014), García Ruescas (2000), Melendreras (2003), Rodríguez Martín (2007), Quintas Froufe (2008), Ramos Frendo (2009), Brasas Egido (2010), Bilbao Salsidua (2013), entre otros.

Por otra parte, la escasa investigación sobre Penagos procede del ámbito de la historia del arte, pero no así desde la publicidad, donde se echan en falta estudios monográficos sobre un artista cuya obra fue mayoritariamente publicitaria. Como dice Pérez Rojas (2006), la publicidad fue uno de los más importantes trampolines de Penagos y su debut en las páginas de las revistas gráficas fue a través de la publicidad para los productos de higiene y belleza.

Convengamos, por tanto, en que existe una laguna de investigación que este artículo intentará paliar ofreciendo un estudio de la iconografía publicitaria esparcida en la revista gráfica La Esfera. En su elección ha influido la excepcionalidad de la revista (Seoane y Sáiz, 1998; Pérez Rojas, 1990; Desvois, 1977; Gómez Aparicio, 1974, Sánchez Vigil, 2003), la cantidad y calidad de los dibujos publicitarios y el testimonio gráfico que ofrece la publicación de la transformación que en España, y concretamente en Madrid, se inicia en los años veinte; modernización, sin duda, a la que contribuyeron aquellas "mujercitas" de Penagos.

Queda abierta, pues, una línea de investigación sobre la obra comercial de Rafael Penagos, que viene a sumarse a la existente sobre otros dibujantes de su época, por ejemplo Federico Ribas (Quintas Froufe, 2011, 2012) o José Loygorri (Brasas Egido, 2010).

\section{Objetivos y metodología}

Los objetivos del presente artículo son, en primer lugar, recopilar la producción publicitaria de Rafael Penagos en la revista gráfica La Esfera (1915-1931), quedando excluidas el resto de ilustraciones gráficas (portadas, páginas artísticas e ilustraciones de textos literarios), ya que no son objeto de esta investigación.

En segundo lugar, efectuar un análisis de contenido de las ilustraciones comerciales para la perfumería Floralia, tanto en portadas como en otros espacios de la revista, con objeto de analizar las características publicitarias y el modelo femenino tan vinculado a la moda creado por Penagos.

La metodología empleada para este trabajo se basa por una parte, en la revisión bibliográfica y hemerográfica de fuentes primarias: los catálogos de las exposiciones y 
la revista La Esfera y, por otra, en el análisis de contenido teniendo como referentes a Bardin (1991) y Krippendorff (1990).

Para la recopilación se han utilizado los fondos hemerográficos de la Biblioteca Digital Hispánica (Biblioteca Nacional), concretamente 889 números de la revista La Esfera desde el número uno del 3 de enero de 1915 hasta el último número del 17 de enero de 1931 excepto 25 números, del 26 de diciembre de 1925 al 3 de julio de 1926 (no 626 al no651), que faltan de los fondos de la hemeroteca digital.

En el periodo consultado se han localizado 38 dibujos comerciales de Penagos, prácticamente todos para la perfumería Floralia. Sólo tres corresponden a otras marcas comerciales: dos proceden del concurso de carteles para el jabón Heno de Pravia de 1916 y el otro, de 31 de enero de 1925, lo realizó para automóviles Lincoln.

El análisis de contenido se ha aplicado a 35 unidades de análisis correspondientes a las ilustraciones para Floralia. A continuación se han articulado seis variables en función de los objetivos de la investigación, a saber, aspectos formales del anuncio (tamaño, color/blanco y negro, firmado/sin firma); idea gráfica del anuncio; figura protagonista (mujer sola/acompañada); escenario del anuncio (ámbito privado/público, representación gráfica del producto, envase); tipo de mujer que representa (folklórica/religiosa, moderna/tradicional, mitológica/oriental); texto (inserto en el dibujo/faldón),(marca, producto, precio, lugar de venta y reclamo), con las que se ha diseñado la ficha de análisis.

\section{Aproximación biográfica}

Rafael Penagos (1889-1954) nace en Madrid en el seno de una familia de la clase media en un hotelito de uno de los barrios periféricos de la ciudad. Sus dotes artísticas se manifiestan a edad temprana, en 1900 decide matricularse en la Escuela Superior de Artes e Industrias y cuatro años después ingresa en la Escuela de Bellas Artes de San Fernando obteniendo un magnífico expediente en ambas instituciones.

La sólida formación recibida y su talento natural para el dibujo le hacen merecedor de numerosos premios en los concursos de carteles que proliferan en España en las primeras décadas del siglo XX. En 1909 se presenta por primera vez al concurso de carteles del Círculo de Bellas Artes de Madrid, concurso que ganaría posteriormente en 1911, 1912 y 1916.

Por esos años comienza a frecuentar las tertulias de los cafés madrileños como el Nuevo Café de Levante, donde se reúnen escritores y artistas en torno a Valle-Inclán. Este ambiente intelectual y bohemio dejará huella en el dibujante, como lo hará su 
estancia de año y medio en París becado por la Junta de Ampliación de Estudios. Precisamente desde París envía varios carteles al concurso convocado en 1913 por la marca de chocolates Amatller de Barcelona, en el que obtiene el primero, segundo y cuarto premio.

Tras unos meses en Londres regresa a Madrid y en 1915 instala su estudio enfrente del parque del Retiro; desde allí emprende una intensa actividad comercial para dos marcas de perfumería: Gal y, sobre todo, Floralia e inicia sus colaboraciones publicitarias en las revistas ilustradas más importantes del momento: La Esfera, Nuevo Mundo, Blanco y Negro, Mundo Gráfico, España y el diario ABC. Al mismo tiempo ilustra las portadas de los célebres Cuentos de Calleja.

Mientras tanto prosigue su participación en concursos de carteles y en 1916 gana el certamen convocado por la casa Gal para promocionar el jabón Heno de Pravia, compartiendo el premio con Federico Ribas y Bartolozzi, eternos amigos y rivales. Los carteles premiados aparecen en las portadas de la revista gráfica La Esfera, que había adquirido los derechos de publicación. Por entonces Penagos colabora asiduamente en las páginas publicitarias de La Esfera.

En 1925 es ya un artista consagrado: ese año recibe la medalla de oro en la Exposición Internacional de Arte Decorativo de París y al año siguiente se alza con el primer premio en el concurso de carteles para anunciar la Exposición Iberoamericana de Barcelona y Sevilla.

Durante las décadas veinte y treinta continúa su actividad publicitaria con carteles para el cine, ilustraciones para editoriales y para nuevas revistas gráficas como Estampa y Crónica.

A finales de los años veinte se convierte en el ilustrador habitual de la casa de discos Regal realizando las portadas de los suplementos, folletos, carteles o cubiertas de discos para publicitar la marca.

Si bien no necesitaba mayor reconocimiento, pues su prestigio era indiscutible, en 1935 gana con el número uno las oposiciones a catedrático de Dibujo del Instituto Cervantes de Madrid, añadiendo así un título oficial a su carrera.

Después de ejercer como profesor de dibujo en distintos institutos españoles, en 1948 viaja a América, donde colabora en varias publicaciones como la revista argentina Atlántida y en 1953 regresa a España. Un año después muere en Madrid, ciudad de la que fue su principal cronista gráfico en los años veinte y treinta del siglo XX. 


\section{Floralia y la publicidad artística}

Penagos trabajó regularmente para diferentes anunciantes comerciales como la marca de discos Regal o la editorial Calleja, si bien donde desarrolló la mayor parte de su actividad publicitaria fue en el sector de la perfumería: Gal y Floralia.

Y es que en los años veinte la industria perfumera era la más desarrollada de España, abierta ya a los mercados internacionales y donde la publicidad formaba parte de su estrategia de crecimiento organizacional. Prat Gaballí (1934: 355) hablaba de un presupuesto de publicidad que oscilaba alrededor de los 4 millones de pesetas. Y Silvio Lago (1917:35), seudónimo de José Francés ${ }^{1}$, reconocía que el crecimiento económico de tres empresas perfumeras españolas (Gal, Floralia y Myrurgia) guardaba relación directa con los gastos en publicidad.

El primer empresario que contó con la publicidad para crear una imagen de marca fue Salvador Echeandía, fundador en 1903 de la casa Gal, pero no sería el único. En 1915 Alejandro Berenguer y Pascual Flaubel, que habían creado en 1914 Perfumería Floralia $^{2}$, iniciaban una campaña publicitaria en la revista La Esfera en la que colaboraron los principales dibujantes del momento.

A lo largo de dos décadas la competencia entre Gal y Floralia se mide en los anuncios ilustrados de las mejores publicaciones de la época (La Esfera, Nuevo Mundo, Blanco y Negro) y en la calidad artística de sus dibujantes. Hasta tal punto fue notoria la publicidad artística de Floralia que la historia del dibujo español en el primer cuarto de siglo puede seguirse a través de las campañas de Floralia de entonces: Penagos, Bartolozzi, Aristo Téllez, Varela de Seijas, Bujados, Dubón, Oliver, Vázquez calleja, KHito, Juan José... (Arte Comercial, 1950:25). Según José Francés, no había un solo dibujante español que no hubiese publicado sus creaciones por mediación de la casa Floralia.

Qué duda cabe que los anuncios ilustrados para las casas Gal y Floralia supusieron el lanzamiento de aquellos dibujantes y su principal sostén económico, además de un medio de difusión del art déco. En opinión de Pérez Rojas (2006): "la historia del diseño gráfico art déco en España no hubiera sido lo que fue sin el apoyo de la publicidad de las perfumerías". Pero no hay que olvidar el rol que tuvieron las revistas gráficas, que sirvieron de soporte a la publicidad artística en unos años de máxima difusión de estas publicaciones; un ejemplo: los carteles ganadores del concurso del

\footnotetext{
${ }^{1}$ José Francés era el crítico de arte de La Esfera y El Año Artístico y secretario de la Academia de Bellas Artes de San Fernando. Por aquel tiempo tuvo un papel relevante en el movimiento asociativo en defensa del dibujante. Firmaba con el seudónimo de Silvio Lago.

${ }^{2}$ Floralia, no pudiendo hacer frente a la fuerte competencia de Gal, en 1930 fue adquirida por esta gran empresa perfumera.
} 
jabón Heno de Pravia de 1916 fueron portada de La Esfera y, por este medio, lograrían llegar al gran público.

Al mismo tiempo, la combinación arte-publicidad resultó beneficiosa para las empresas perfumeras, que vieron cómo aumentaba la demanda de sus productos a la vez que ejercían de mecenas de artistas.

En mayo de 1917 Floralia, en una operación de marketing, firma un acuerdo con La Esfera para iniciar una página dedicada a su perfumería, titulada "Páginas de la Perfumería Floralia", en la que irán apareciendo, sucesivamente, los distintos productos de la marca; página que enseguida pasa a denominarse "Modas de Floralia" con objeto de asociar los productos de belleza a la moda ${ }^{3}$. Conviene recordar que en los años veinte la moda experimenta un gran cambio en relación con el decenio anterior: las creaciones innovadoras de modistos como Poiret y Chanel llegan a España a través de nuestros dibujantes, muy pendientes de la alta costura parisina. Como señala Pérez Rojas (1990:96), uno de los rasgos distintivos de los ilustradores gráficos es su interés por reflejar mujeres a la última, con aire chic y mundano.

En definitiva, la estrategia publicitaria de Floralia vino a renovar las artes gráficas en España; sus novedosas ilustraciones publicitarias contribuyeron a la modernización del anuncio, pues la empresa daba libertad a los artistas con la única condición de preservar el buen gusto y la armonía. De este modo, el arte decorativo español se fue imponiendo entre el público "con mayor eficacia que en exposiciones aisladas o que en ilustraciones de artículos literarios, pasando de las planas consagradas a la publicidad a las primeras de los semanarios más prestigiosos" (Lago, 1917:35).

Se trataba de anuncios a página completa con modernas imágenes femeninas de trazo suave y elegante, en las que primaba la sencillez y la distinción, hasta entonces algo inusual en la ilustración publicitaria pródiga en orlas y otros adornos. Parece ser que Gal, al comparar estos anuncios con los que venía realizando Ehrmann, su colaborador habitual (Alvarado y De Andrés, 1998: 32), decidió, en adelante, confiar la publicidad de sus productos a dibujantes jóvenes que empezaban a mostrar su talento en concursos y exposiciones.

Además de los anuncios ilustrados Floralia utilizó otras formas de promoción como fueron los concursos, una costumbre entre las marcas perfumeras; por ejemplo, el convocado por Gal en 1916 o el de La Toja de 1924. El primer concurso que organizó Floralia, conocido como el concurso de la muñeca, se abrió el 5 de enero de 1915, cuyo premio consistía en una muñeca conocida como Floralia y valorada en 1300 pesetas.

\footnotetext{
${ }^{3}$ Los dibujos, que representaban los avances de la moda, se acompañaban de largos textos donde se relacionaban los modelos con los productos de Floralia. La autora, tanto de los dibujos como de los textos, era Mar de Mun, seudónimo de María de Munarri, colaboradora del Departamento de Publicidad de Floralia ( $A B C, 3 / 5 / 1919: 2)$
} 
Dicha muñeca iba acompañada de una canastilla, una medalla de oro con cadena y un imperdible de oro y brillantes. Al año siguiente se celebró un concurso infantil de dibujos cuyo tema era la publicidad y, finalmente, un concurso de fotografía.

Si Gal tuvo en Federico Ribas su mejor exponente, Floralia, aunque contó con muchos y magníficos dibujantes, encontró en Rafael Penagos su principal colaborador, autor de la mayor parte de sus dibujos publicitarios. De hecho, su estreno en las revistas gráficas La Esfera y Nuevo Mundo, publicaciones en las que participó más asiduamente, fue con esta empresa.

Su colaboración en La Esfera se inicia 20 de marzo de 1915, pero su relación con Floralia se intensifica a partir de 1916 cuando gana junto a Bartolozzi y Ribas el primer premio del concurso de Gal para dar a conocer el jabón Heno de Pravia. El gran acontecimiento artístico y comercial que supuso el concurso hace que, a partir de ese momento, nada sea igual para los tres artistas: Federico Ribas es nombrado Director Artístico de Gal y Bartolozzi y Penagos fueron contratados por Floralia ${ }^{4}$.

Así pues, Penagos se incorpora al Departamento de Publicidad de Floralia que dirigía, en la parte artística, Karikato (seudónimo del dibujante Cesáreo del Villar) y en la redacción de anuncios el escritor Emilio Morales de Azevedo. Nuestro autor acudía diariamente a la sede de Floralia de la calle Granada, 2, allí le entregaban el mensaje publicitario y luego, en su estudio de la calle Alfonso XII, esbozaba la idea gráfica del anuncio.

El producto estrella era el jabón "Flores del Campo", al que se sumó la colonia; después vinieron otros productos: los polvos de arroz, el dentífrico "Oxenthol", el desodorante "Sudoral", el tónico para el cabello "Ron Quina", la brillantina y el extracto y más adelante, la barra de labios "Humo de Sándalo" y "Sanatorina", un producto para la jaqueca y las molestias propias de la mujer.

El reclamo publicitario era la muchachita del dibujo, cuya frescura y estilo tenían gran éxito entre las mujeres, que veían en ella un espejo donde mirarse en unos tiempos de cambio en la moda y en las costumbres sociales.

Desde 1920 no aparecen anuncios de Floralia ni ilustraciones de Penagos, puede ser que Floralia priorizara otros soportes como la prensa o que no pudiera asumir el coste publicitario en un mercado tan competitivo como el sector de la perfumería. En cambio, Penagos no abandonó La Esfera, si bien dejó de colaborar con dibujos publicitarios, pero siguió ilustrando con regularidad los textos literarios de la revista y firmó algunas portadas.

\footnotetext{
${ }^{4}$ En las primeras décadas del siglo XX había pocas agencias de publicidad y las que había no hacían creatividad ni tratamientos artísticos. Los anunciantes encargaban directamente las ilustraciones a los dibujantes, de forma puntual y sin que hubiese una vinculación estable con la empresa (Eguizábal, 2014:152).
} 
Por otro lado, el auge de la ilustración publicitaria tiene lugar en los primeros decenios del siglo XX y después comienza la decadencia de la publicidad artística. Como apunta Pérez Rojas (1990,155), en 1926 se echan en falta aquellos anuncios de Gal y Floralia que animaban las páginas de La Esfera.

\section{Resultados del análisis de los dibujos publicitarios}

Penagos inicia su colaboración para Floralia el 20 de marzo de 1915 con una imagen femenina estilizada y bien vestida, donde la elegancia es el reclamo. Sus ilustraciones carecen de periodicidad porque, a diferencia de Federico Ribas en Gal, Penagos compartía los encargos de Floralia con otros artistas. Generalmente realizaba un dibujo al mes y ciertos meses, en 1915 y 1917, uno por semana. Su último dibujo publicitario para esta marca es del 13 de diciembre de 1919, en esta ocasión los productos de la perfumería se asocian a una mujer de buen porte y muy española de pelo negro y ojos profundos, con peineta y mantón, que desde sus aposentos contempla una noche estrellada.

Las colaboraciones publicitarias son dibujos a página completa, en color, en los que se aprecia con letra mayúscula la rúbrica de Penagos, que tenía por costumbre firmar las ilustraciones. Estos dibujos no se publicaban en los espacios publicitarios de la revista ni se mezclaban con otros anuncios, sino que -por lo general- estaban reservados a la última página, a veces iban en el interior y pocas en portada, lo que significa, por un lado, que eran considerados colaboraciones artísticas (anuncios de autor) destinadas a un lugar preferente $y$, por otro, que Floralia no escatimaba en gasto publicitario a cambio de una exclusiva imagen de marca.

Por lo que hace a la idea gráfica del anuncio, se han contabilizado nueve conceptos diferentes con los que se asocia el dibujo, a saber, elegancia, distinción, modernidad, deporte, playa, campo, salud, belleza e higiene. Ahora bien, si lo normal de estas ilustraciones es que la idea gráfica esté en consonancia con el reclamo, no siempre sucede así, muchas veces los dibujos no dicen nada, son puro arte; por ejemplo, la imagen invernal de una jovencita en la nieve (figura 1). Hay que tener en cuenta que el artista gozaba de plena libertad para interpretar a lápiz el mensaje publicitario y en ese dibujo radica el atractivo del anuncio. Las empresas perfumeras lo sabían y acudían a los artistas del momento, cuyas bellas ilustraciones otorgaban un marchamo de calidad a la marca. 


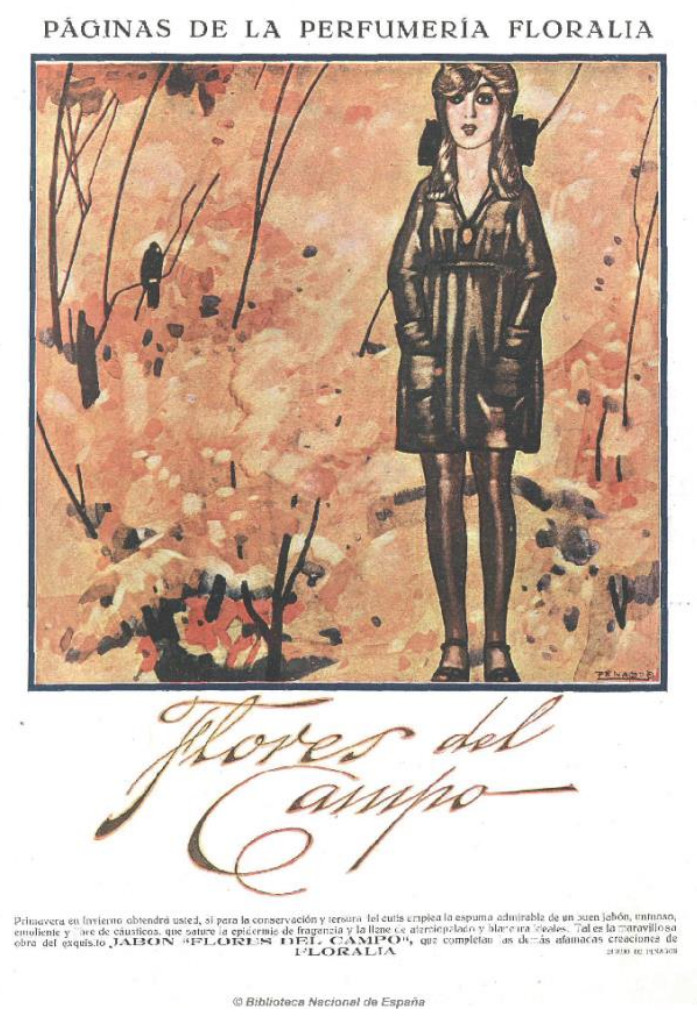

Figura 1: La Esfera, 23/06/1917

En cuanto a la protagonista de los dibujos, el análisis nos revela que se trata de una mujer, bien sola o bien acompañada, cuya personalidad destaca por encima de accesorios y situaciones. Una mujer de ojos sombreados y mirada profunda, labios rojos, con pelo corto, largo o moño pero morena; de figura estilizada y talle esbelto, decidida, graciosa, ingenua o sensual. La mujer que dibuja Penagos con frecuencia aparece sola (24 ilustraciones) ${ }^{5}$ porque es la protagonista absoluta de la escena en la que deben mirarse las jóvenes de la época. Por otra parte, esa es la imagen con la que quiere identificarse Floralia.

Penagos sitúa a sus muchachitas en dos tipos de escenarios que representan la vida cotidiana de la burguesía. Unas veces elige el ámbito público (17) y otras, el ámbito privado (11), dependiendo del modelo femenino que desea difundir. El ámbito público le permite recrear una imagen alegre, independiente, elegante, distinguida, moderna práctica, sociable; una mujer que frecuenta el teatro, el café, el restaurante; practica deporte, viaja sola, conversa; en definitiva, que se desenvuelve como pez en el agua en una sociedad cosmopolita. En este grupo se hallan las escenas al aire libre, por ejemplo, paseando por el campo (5), disfrutando de la playa (3), practicando deporte (3), conversando en la calle (1), al abandonar el hotel (1), bailando en un café-baile (1), en el teatro (2).

\footnotetext{
${ }^{5}$ A partir de ahora el número de ilustraciones se indicará con un número entre paréntesis.
} 
En las escenas de interior presenta una mujer sensual, atractiva, insinuante, coqueta, saludable; que se cuida, se preocupa por su aspecto físico y dedica tiempo al arreglo personal. Escenas que tienen lugar en la intimidad de un tocador (4), durante el baño (6) o en su estancia (2). En estos escenarios repite los mismos objetos, por ejemplo el espejo (4), la palangana (3), el lavabo (4), la toalla o albornoz (4), la caja o el frasco (9).

Tanto en escenario público como privado, se trata de un prototipo femenino novedoso en España que hace furor en la Europa de los años 20.

Además de los anteriores existen otro tipo de dibujos, sin escenario aparente, que evocan a la mujer española, hermosa, con clase, que despierta admiración por donde pasa; para representar este modelo femenino recurre al traje regional y a la mantilla en una exaltación del regionalismo hispano tan en boga en los artistas de la época. En este grupo se encuadran tres ilustraciones sobre fondo blanco, gris o negro que, por la postura de la protagonista, se asemejan a un retrato (figura 2).

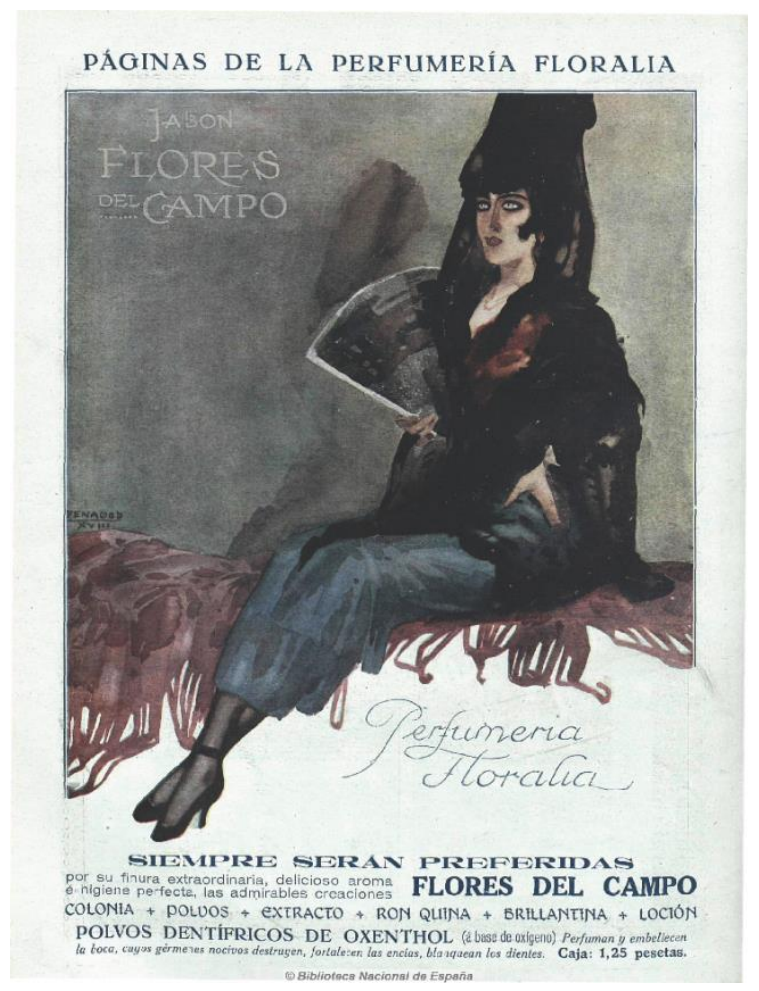

Figura 2: La Esfera, 25/05/1918

En cuarto lugar están las ilustraciones que tienen por escenario la antigüedad clásica y lo oriental y exótico, una corriente puesta en valor en los primeros decenios del siglo $X X$, que tuvo muchos seguidores en nuestro país; y las incursiones en el ámbito de la literatura y el carnaval. A este grupo pertenecen los dibujos femeninos neogriegos (1), arlequines (2), personajes literarios (Margarita Gautier) y orientales (1). 
Finalmente, subrayar el carácter comercial de los dibujos, los productos de Floralia: jabones, colonias, polvos, etc., con presencia en el escenario del dibujo, en dos ocasiones llevan el nombre de la marca en los envases (figura 3), todo un guiño a la empresa para la que trabajaba.

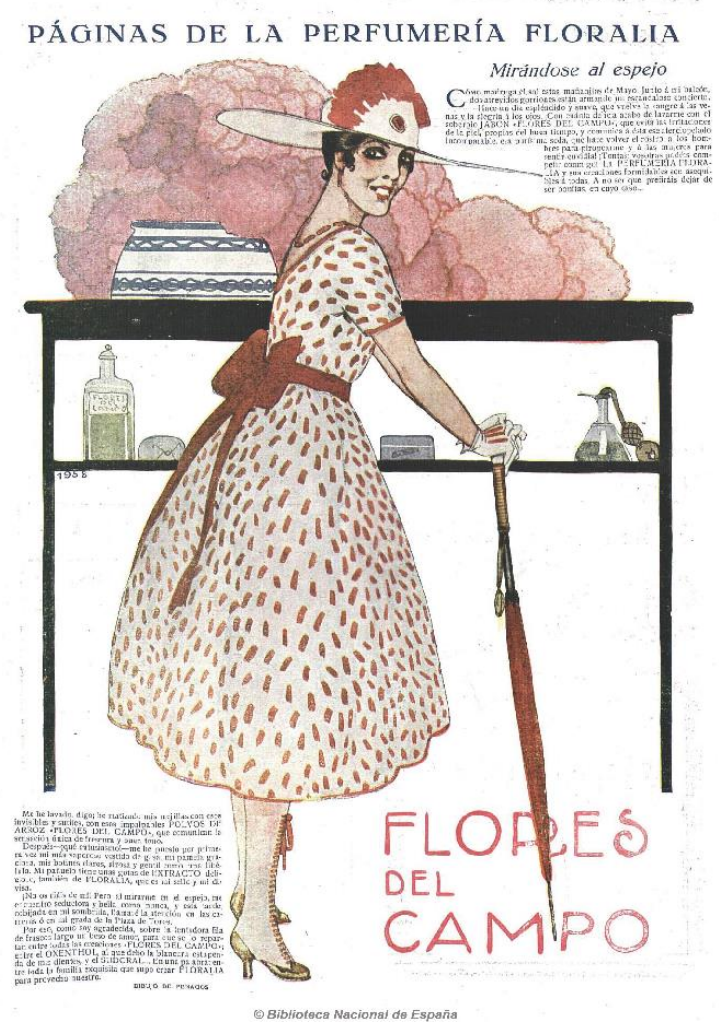

Figura 3: La Esfera, 16/06/1917

Veamos a continuación cómo representó Penagos a la mujer en las ilustraciones publicitarias de La Esfera.

Es sabido que Penagos creo un prototipo femenino que en España no existía, pero acabaría imponiéndose entre la burguesía madrileña, la cual empezaba a adoptar los cambios procedentes de otras capitales europeas. Pues bien, esta nueva Eva está presente desde 1915 en su producción publicitaria, recordemos que sus primeras colaboraciones en las revistas gráficas fueron ilustraciones comerciales de productos de belleza e higiene. Por tanto, es natural que la mayoría de los dibujos para Floralia (31) correspondan a esa imagen de mujer moderna, cosmopolita, vestida a la última moda, elegante, joven y deportista; con zapatos de tacón, sombrero, guantes, paraguas, lazos y pañuelos. Ningún detalle escapa a su atención, pendiente como estaba de la moda y sabiendo que esta era el principal atractivo para las lectoras de la revista y consumidoras de los productos de perfumería. 
Sin embargo, Penagos dibujó también otro tipo de mujer muy frecuente entre los artistas contemporáneos, un ejemplo, las portadas de Ribas en La Esfera para el jabón Heno de Pravia con los trajes de cada una de las regiones españolas.

En los dibujos para Floralia, Penagos representó una mujer española renovada, lejos de los tópicos en los que se suele recaer cuando se refiere a España. Mujeres con mantilla y abanico (3), cofia y delantal (2), maternal (1) pero sobrias, distinguidas, castizas y a la vez actuales.

Analicemos ahora la parte textual de las ilustraciones publicitarias, que son las que indican la evolución de la publicidad. En este punto, nos encontramos con dos posibilidades: que el texto esté inserto en el dibujo o que vaya en un faldón aparte. En la mayoría de las ilustraciones (26) el texto forma parte del dibujo, aunque solamente figura el título del producto Flores del Campo (17); las otras nueve ilustraciones incluyen también precio, marca, nombre del producto/s, lugar de venta y reclamo.

Cuando el texto va en un faldón aparte (18), la información es más exhaustiva y el reclamo, muchas veces, adquiere un tono literario. En este caso nos encontramos con tres tipos de textos: el primero, con información publicitaria (marca, producto, precio y lugar de venta) y un pequeño reclamo (3), dos corresponden a 1915 y uno a 1918; el segundo, con escasa información publicitaria (únicamente productos) y un reclamo más extenso (17), datan de 1915, 1918 y 1919; y el tercero, donde la información publicitaria (productos) se mezcla con una pequeña historia (12) que hace el texto más extenso. Estas historias o cuentos tienen una protagonista con nombre propio: Colombina, Margarita, Caperucita, Claudina, Frivolina, Marlina, Diavolina o Rosita que guarda relación con el argumento. Y un título apropiado a la narración: "La balada alegre", "Margarita Gautier no era un drama, sino un idilio", "Su secreto", "Mirándose al espejo", "Desde arriba”, "Una sportswooman”, "En la playa”, "Frivolina viaja”, "Para vencer en amor" (figura 4), "Leyenda y realidad", "Al vuelo" y "El moderno árbol de Noel". Estas ilustraciones corresponden a 1917. 


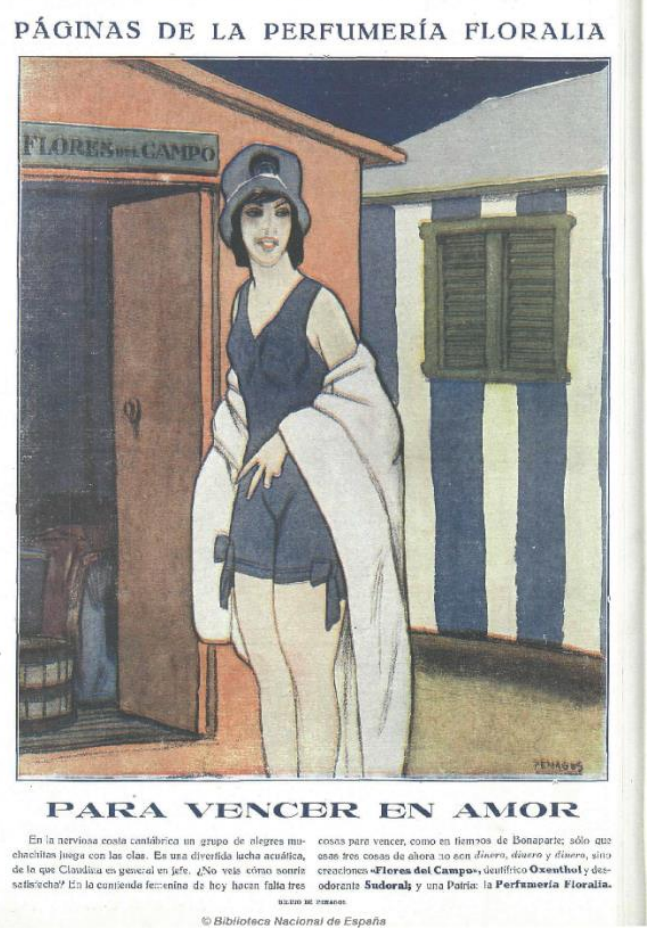

Figura 4: La Esfera, 4/08/1917

Este modo de elaborar el anuncio es propio de la publicidad artística que acostumbra a encargar, tanto el dibujo como el texto, a excelentes dibujantes y escritores dotados de una gran creatividad.

Por último, señalar que a partir de mayo de 1917 todos los anuncios se inscriben bajo el rótulo "Páginas de la Perfumería Floralia", en total son 23 ilustraciones.

\section{Conclusiones}

Penagos colaboró asiduamente, entre 1915 y 1920, en La Esfera con dibujos para Floralia. Sus ilustraciones carecen de periodicidad porque, a diferencia de Federico Ribas en Gal, Penagos compartía los encargos de Floralia con otros artistas. Normalmente realizaba un dibujo al mes y durante ciertos meses, en 1915 y 1917, uno por semana.

Aquellas ilustraciones, a página completa, en color y firmadas no se publicaban en los espacios publicitarios de la revista ni se mezclaban con otros anuncios, sino que -por lo general- estaban reservados a la última página, porque eran consideradas colaboraciones artísticas (anuncios de autor) destinadas a un lugar preferente de la revista. 
Los dibujos de Penagos iban acompañados de textos publicitarios singulares, por cuanto no se trataba de mera información publicitaria, sino que a lo largo de 1917 se componen de pequeñas historias o cuentos. Este modo de elaborar el anuncio es una peculiaridad de la publicidad artística, que acudía a dibujantes y escritores excelentes dotados de una gran creatividad.

La idea gráfica de los anuncios de Penagos para Floralia se asocia a conceptos como elegancia, distinción, modernidad, deporte, playa, campo, salud, belleza e higiene. La protagonista es siempre una mujer, cuya personalidad destaca por encima de accesorios y situaciones. Una mujer de mirada profunda, labios rojos, morena, dedos largos, de figura estilizada, decidida, graciosa, ingenua o sensual.

Las muchachitas de Penagos aparecen en escenarios de ámbito público, que le permite recrear una imagen femenina alegre, independiente, elegante, distinguida, moderna práctica, sociable y cosmopolita; o en la intimidad, donde presenta una mujer sensual, atractiva, insinuante, coqueta y saludable.

Siguiendo la corriente artística en boga Penagos representó a la mujer en escenarios de la antigüedad clásica, orientales y exóticos o referentes al ámbito de la literatura y el carnaval. Y como otros dibujantes de la época, por ejemplo Federico Ribas, también representó a la mujer española con mantilla y abanico, moño y mantón pero a diferencia de ellos Penagos ofreció una imagen renovada de la mujer española: sobria, distinguida y castiza, otra de sus aportaciones no menor.

Su vinculación con Floralia se estabiliza a partir de 1916, cuando entra a formar parte de su importante Departamento de Publicidad. En este departamento se gestionó la compra de un espacio publicitario en La Esfera que, desde mayo de 1917, se titulaba "Paginas de la Perfumería Floralia" y que enseguida pasó a denominarse "Modas de Floralia".

Pues bien, Penagos, que estuvo siempre muy atento a las tendencias de la vestimenta femenina, no sólo contribuyó a la difusión de la moda parisina entre la burguesía madrileña como hicieron otros artistas: Federico Ribas, José Zamora o Bartolozzi, sino que, además, -con una interpretación personalísima de la silueta- creó un modelo femenino característico que se advierte ya en los anuncios ilustrados para Floralia y que constituye una de sus principales aportaciones. 


\section{Referencias bibliográficas}

ALVARADO, M.C. DE ANDRÉS, S. (1998): "Gal: un siglo de perfumería, un siglo de publicidad", en Publifilia. Revista de culturas publicitarias, no 6, Segovia, Colegio Universitario de Segovia, pp.23-49.

BARDIN, L. (1991): Análisis de contenido, Madrid, Akal.

BIILBAO SALSIDUA, M. (2013): “Discos Regal. Aproximación a la historia de un sello discográfico pionero en España (1923-1935)”, en Musiker, no 20, pp.143-166.

BRASAS EGIDO, J.C. (2010): José Loygorri. Dibujante Art Déco, Valladolid, Diputación de Valladolid.

CARULLA, J. \& CARULLA, A. (1999): La publicidad en 2000 carteles, Vol I, Barcelona, Postermil.

CAMPOY, A.M. (1983): Penagos 1889-1954. Aproximación al creador más significativo de su tiempo, Madrid, Espasa-Calpe.

DE ANDRÉS DEL CAMPO, S. (1985): “Del modernismo al Déco en la publicidad española", en 100 años del cartel español. Publicidad y Comercio (1875-1975), Madrid, Centro Cultural Conde Duque, Ayuntamiento de Madrid, pp.21-32.

DESVOIS, J.M. (1977): La prensa en España (1900-1931), Madrid, Siglo Veintiuno de España.

DIEGO, E. de (1983): "Ilustraciones de Penagos. Déco y reminiscencia finisecular", en Goya: Revista de arte, no 175-176, pp.32-39.

EGUIZÁBAL, R. (2014): El cartel en España, Madrid, Cátedra.

- (1998): Historia de la Publicidad, Madrid, Eresma\&Celeste.

GARCÍA RUESCAS, F. (2000): Historia de la Publicidad y del arte comercial en España. Desde tiempos remotos hasta el final del siglo XX, Madrid, Arus.

GÓMEZ APARICIO, P. (1974): Historia del periodismo español. De las guerras coloniales a la Dictadura, Madrid, Editora Nacional.

KRIPPENDORFF, K. (1990): Metodología de análisis de contenido: teoría y práctica, Barcelona, Paidós Comunicación.

LAGO, S. "La evolución artística del anuncio" en La Esfera, 6 de enero de 1917, no 158, p.35.

LOZANO BARTOLOZZI, M. (1992): “Los carteles y el arte publicitario de Salvador Bartolozzi (1882-1950)", en Norba: Revista de arte, no12, Badajoz, Universidad 
de Extremadura, pp.187-202. Disponible en Internet $(2 / 9 / 2014)$ http://dialnet.unirioja.es/servlet/oaiart?codigo=107454

MELENDRERAS, E. (2003): "15 carteles para la historia", en Publifilia. Revista de culturas publicitarias, no 7, Segovia, Colegio Universitario de Segovia, pp.65-89.

PÉREZ ROJAS, F. J. (2006): Rafael de Penagos en las Colecciones MAPFRE, FUNDACIÓN MAPFRE, Madrid, Instituto de Cultura. Disponible en Internet (24/1/2015): www.coleccionesfundacionmapfre.org/artistas/rafael_penagos (1990): Art Déco en España, Madrid, Cátedra.

PRAT GABALLÍ, P. (1934): Publicidad racional, Barcelona, Labor.

QUINTAS FROUFE, E. (2008): “Origen y proliferación de los concursos de carteles a principios del siglo XX: el concurso de la perfumería Gal (1916)", en Área Abierta, no 21, Madrid, Universidad Complutense, pp.1-13. Disponible en Internet (4/7/2014)

http://www.revistas.ucm.es/index.php/ARAB/article/viewFile/.../4133

- (2011): Federico Ribas Montenegro: obra gráfica, editorial y publicitaria. Análisis y catalogación documental (1916-1936), Tesis doctoral, Universidad de Vigo.

- (2012): "La evolución de la comunicación publicitaria: Análisis de la obra de Federico Ribas para Perfumería Gal (1916-1936)", en Revista Latina de Comunicación Social, no 67, La Laguna (Tenerife), Universidad de La Laguna, pp.439-469. Disponible en Internet (2/11/2015) http://www.revistalatinacs.org/067/art/963_eva.html

RAMOS FRENDO, E. (2009): “Iconografía publicitaria de una década en Blanco y Negro (1915-1925)", en Cuadernos de arte e iconografía, tomo 18, no 36, pp.449-488.

RODRÍGUEZ MARTíN, N. (2007): "La imagen de la mujer en la publicidad gráfica en España en el primer tercio del siglo XX", en Amador, P., Robledano, J. y Ruiz, R. (editores), $\mathrm{V}$ Jornadas imagen, Cultura y Tecnología, Madrid, Archiviana.

SÁNCHEZ VIGIL, J.M. (2003): La Esfera: ilustración mundial (1914-1931), Madrid, Libris.

SATUÉ, E. (1997): El diseño gráfico en España: historia de una forma comunicativa nueva, Madrid, Alianza Editorial.

SEOANE, M. \& SÁlZ, M.D. (1998): Historia del periodismo en España. 3. El siglo XX: 1898-1936, Madrid, Alianza.

“Modas de Floralia", ABC, 3 de mayo de 1919, p.2 
"Apuntes sobre la publicidad y la perfumería en España", Arte Comercial. Revista técnica de publicidad y organización, no22, año IV, 1950, Madrid, pp.24-27.

BENAVIDES DELGADO, J. (1995): "La presencia de la publicidad en la construcción de la cultura cotidiana" en Especulo. Revista de estudios literarios, nำ1, noviembre de 1995.

Disponible

en

Internet

(4-12-2002):

http://www.ucm.es/info/especulo/numero1/benavid.htm 